\title{
Services écosystémiques et riziculture autour du lac de Tonle Sap, Cambodge
}

\author{
Malyne Neang ${ }^{1, *}$ (i) et Philippe Méral $^{2}$ \\ ${ }^{1}$ ECOLAND, Université Royale d'Agriculture, BP 2696, Phnom Penh, Cambodge \\ 2 IRD, UMR GRED, Université Montpellier 3, 34086 Montpellier, France
}

\begin{abstract}
Résumé - Cet article vise à analyser les services (et dis-services) écosystémiques que la population cambodgienne retire de l'écosystème formé par le lac Tonle Sap et sa grande plaine d'inondation. Caractérisé par un phénomène de flux et de reflux du fleuve Mékong selon la saison des pluies, ce lac, dont la taille varie de un à cinq, est le lieu de la culture du riz, principale activité agricole du pays et denrée alimentaire de sa population. L'étude de cet agroécosystème, réalisé par des enquêtes dans six villages, montre une complexité dans la compréhension de ces services écosystémiques. Certains sont positifs, d'autres négatifs. Certains sont positifs jusqu'à un certain niveau, mais deviennent négatifs par la suite. Certains sont coproduits par la riziculture, qui au fil du temps a façonné l'écosystème. Nous montrons également, à partir d'une analyse des systèmes agraires, que les systèmes de production sont plus ou moins compatibles avec le maintien de ces services.
\end{abstract}

Mots clés : services écosystémiques / dis-services écosystémiques / riziculture / lac de Tonle Sap / système agraire

Abstract - Ecosystem services and rice cropping system around Tonle Sap Lake, Cambodia. This paper aims to analyze the ecosystem services and dis-services that the Cambodian population get from the ecosystem formed by the Tonle Sap Lake and its large flood plain. This lake is characterized by a phenomenon of ebb and flow of the Mekong River according to the rainy season. Its size varies from one to five, and it is the place where rice is cultivated. Rice is the main agricultural activity of the country and the main food of its population. The study of this agro-ecosystem, carried out through surveys in six ricegrowing villages, shows a complexity in the understanding of these ecosystem services. Some are positive, others are negative. Some are positive up to a certain level but become negative afterwards. Some are coproduced by rice cultivation, which over time has shaped the ecosystem. We also show, from an analysis of agrarian systems, that production systems are more or less compatible with maintaining these services.

Keywords: ecosystem services / ecosystem dis-services / rice cropping systems / Tonle Sap Lake / agrarian system

\section{Introduction}

Le lac Tonle Sap (LTS), première « réserve de biosphère» de l'UNESCO au Cambodge, est le plus grand lac d'Asie du Sud-Est (Fig. 1). Alimenté par le Mekong, il agit tel un réservoir de ce fleuve, accueillant sa crue lors de la saison des pluies (de mai à octobre), créant une vaste plaine inondable propice à la riziculture, avant de se rétracter en saison sèche, de novembre à avril. Sa superficie fluctue donc entre 2500 et $15000 \mathrm{~km}^{2}$ selon la saison (Varis et Keskinen, 2006). Ce phénomène naturel facilite la production rizicole autour du lac, mais également en aval de celui-ci. En effet, situé légèrement en amont du delta du Mekong (Vietnam), sa fonction de

\footnotetext{
*Auteur de correspondance : nmalyne@gmail.com
}

réservoir permet de réguler les crues lors des saisons des pluies, de maintenir un flux d'eau douce en saison sèche et d'éviter un apport en eau salée également lors de la saison sèche (Hai et al., 2008).

Par ailleurs, ce mécanisme de flux et de reflux permet au LTS d'être classé parmi les écosystèmes continentaux les plus poissonneux au monde (Varis et al., 2006). Il fournit $60 \%$ des protéines utilisées par la population cambodgienne, qui consomme entre 20 et $60 \mathrm{~kg}$ de poisson par habitant et par an (Baran et Myschowoda, 2008).

L'écosystème du LTS est considéré comme un cas d'école en matière de services écosystémiques retirés par la population locale et régionale (au sens de plusieurs pays voisins, principalement le sud du Vietnam situé en aval) (Dan et al., 2005). La production alimentaire de riz, de poisson, mais aussi 


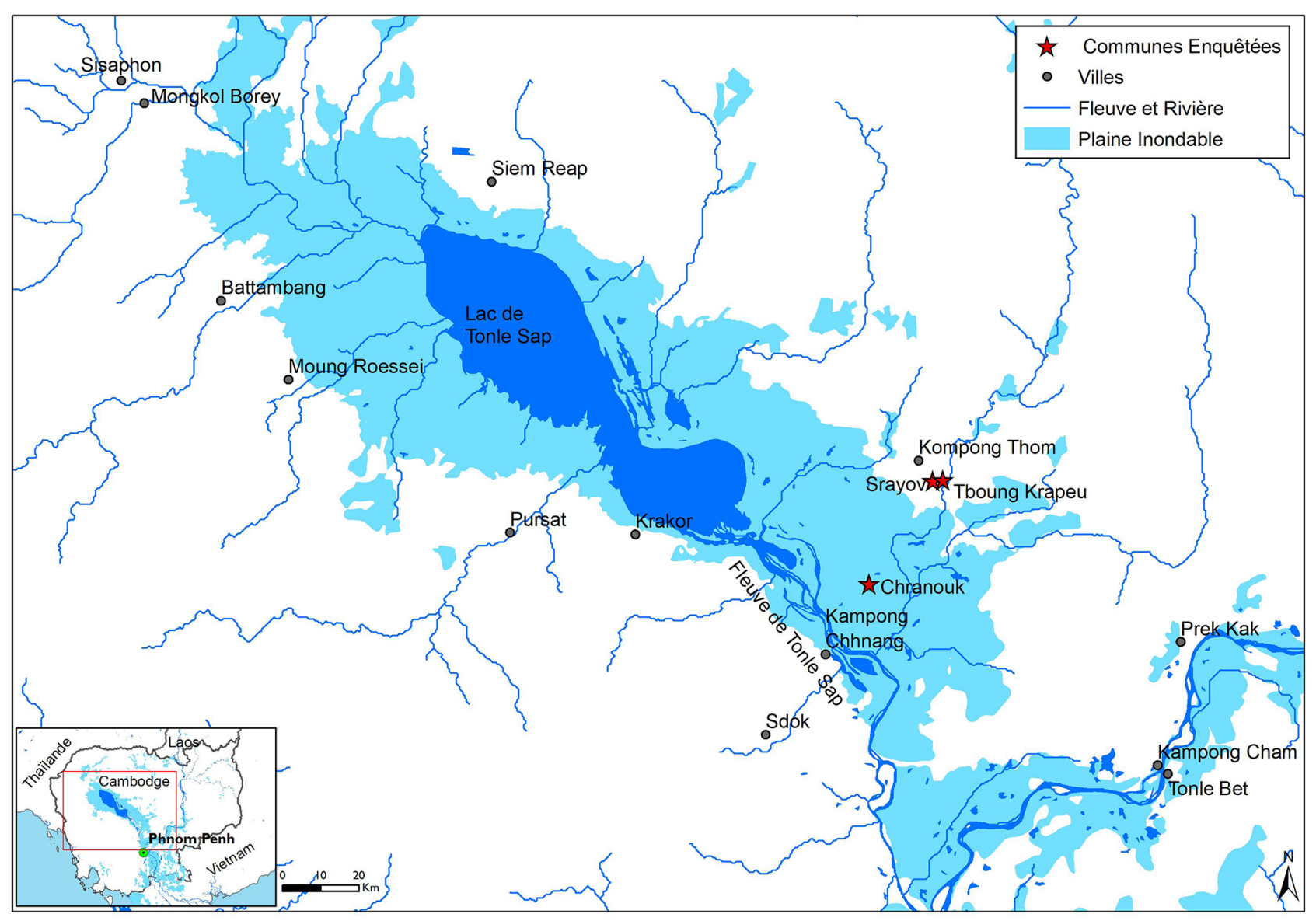

Fig. 1. Le lac de Tonle Sap et sa plaine inondable. Source: Greater Mekong Subregion Information Portal.

Fig. 1. Tonle Sap Lake and its flood plain.

les usages directs du bois des forêts inondées constituent une série de services d'approvisionnement. La régulation des crues, le rôle d'habitat et de frai pour les poissons et les oiseaux sont autant de services de régulation dont bénéficient les Cambodgiens. L'importance culturelle du riz et le rôle récréatif de ce lac constituent également des sources de services culturels. Ainsi, pour ne prendre qu'un exemple, le moment de renversement du flux, phénomène très rare à travers le monde, donne lieu à une fête nationale dite «fête des eaux» qui occasionne festivités nautiques, courses de pirogues et partage d'Ambok (plat traditionnel de riz grillé).

Si ces relations positives sont bien documentées dans la littérature (ADB, 2005), d'autres le sont moins alors qu'elles revêtent un caractère tout autant déterminant à l'échelle locale. Par exemple, le phénomène de flux et de reflux conduit parfois à des inondations et des pertes de production, voire d'habitat (Arias et al., 2012). De même, des niveaux trop élevés du lac facilitent l'entrée d'espèces dangereuses (serpents, crocodiles) dans les villages alentour, réduisent l'accessibilité des routes et fragilisent les conditions de vie des populations riveraines (Brooks et al., 2007). Si les services fournis par l'écosystème du LTS sont bien documentés, il n'en est donc pas de même pour la catégorie des dis-services. De plus, l'aménagement du territoire participe à la co-fourniture de ces services et disservices. Bien comprendre les interactions entre écosystème et activités agricoles (nous appelerons par la suite cette combinaison "agroécosystème») relève donc d'un défi tout autant méthodologique qu'opérationnel. L'objectif de cet article est d'analyser ces interactions sur la base d'un travail de terrain réalisé dans six villages issus de deux communes.

\section{Cadrage théorique et méthodologique}

Power (2010), Swinton et al. (2007) et Zhang et al. (2007) ont proposé des cadres d'analyse sur les relations entre agriculture et services écosystémiques. Bonin et Eloy (2014) ont proposé une synthèse de ces travaux que nous avons reprise (Fig. 2).

Placée au centre, l'agriculture, prise au sens large incluant la foresterie, l'élevage et la pêche, bénéficie de services positifs issus de la nature (pollinisation, etc.), tout en étant contrainte par des dis-services (ravageurs, etc.). De plus, elle coproduit des services positifs (approvisionnement en aliments et fibres) et génère par son activité des dis-services (pollution des eaux), parfois contre elle-même (destruction de ses propres agents pollinisateurs, salinisation des sols, etc.). Ces effets retours créent ainsi une dynamique propre à l'agroécosystème. Tout l'enjeu consiste alors à favoriser une dynamique positive.

Pour analyser ces relations, nous recourons à l'analyse des systèmes agraires. Elle permet, pour un territoire donné, de diagnostiquer ces relations et de proposer des pistes d'une gestion plus durable de l'agroécosystème (Cochet, 2012; 


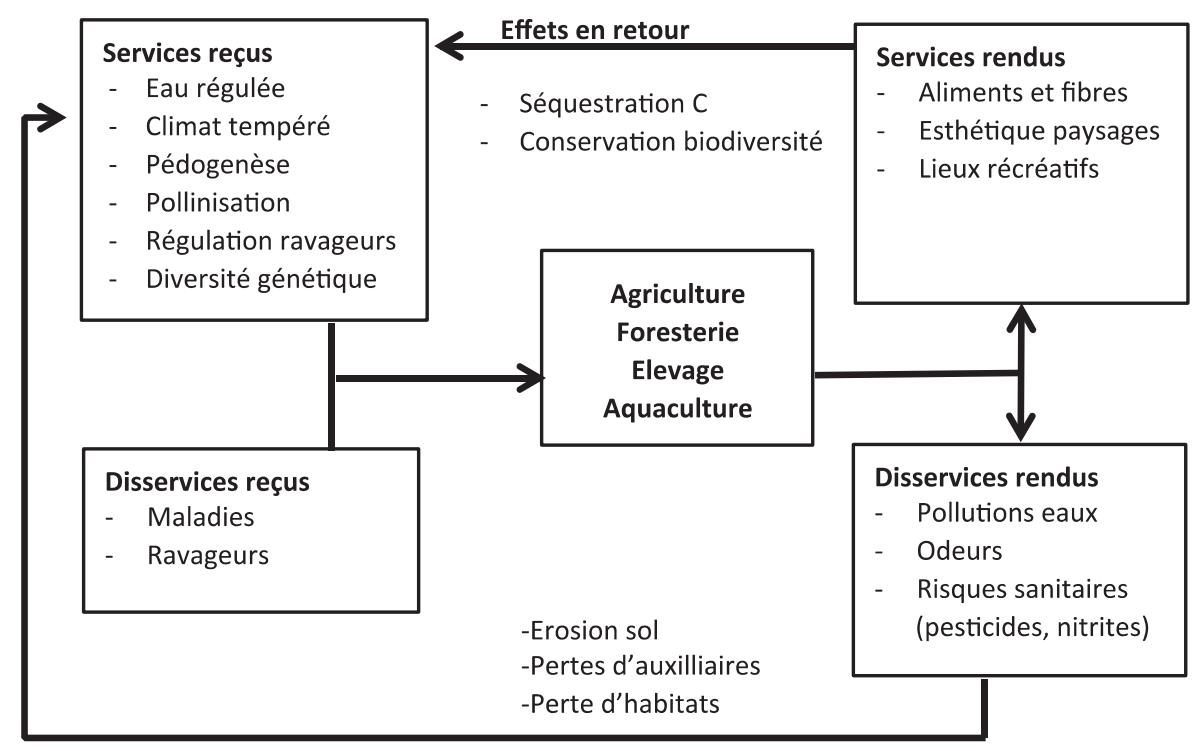

Effets en retour

Fig. 2. L'agriculture, bénéficiaire et fournisseuse de services écosystémiques, subissant ou émettant des «dis-services », et effets en retour (adapté de Bonin et Eloy, 2014 ; Swinton et al., 2007).

Fig. 2. Agriculture, ecosystem services beneficiairy and provider, suffering or emitting "dis-services », and returning effects.

Cochet et al., 2007; Mazoyer et Roudart, 1997). Elle met l'accent sur trois axes de diagnostic : une lecture (notamment écologique) du paysage, une approche historique et une analyse économique de l'exploitation agricole.

L'analyse paysagère a consisté à observer et à comprendre cet agroécosystème. Dans chacun des villages étudiés, les usages et pratiques ont été caractérisés le long de transects perpendiculaires aux rives du lac, puis schématisés sur un diagramme. L'analyse géographique et historique du territoire étudié s'est concentrée sur les évolutions et les facteurs de changement ayant conduit à la situation observée. Enfin, l'analyse économique des exploitations agricoles a été réalisée à partir du calcul des revenus générés par chaque système de production, lui-même composé de plusieurs systèmes de culture (Cochet et Devienne, 2006).

Une quatrième étape analyse les différents systèmes de production identifiés au cours des trois étapes précédentes (analyses paysagère, historique et économique), au regard des trois grandes catégories de services écosystémiques: les services d'approvisionnement, de régulation et culturels (MEA, 2003). Nous tenons compte de la co-production des services et dis-services et nous opérons une sélection adaptée au contexte de notre étude (Tab. 1). Les services d'approvisionnement concernent tout un ensemble de produits alimentaires : riz, poisson, petit gibier, insectes, rats, serpents ainsi que les prélèvements de bois et les plantes et racines. Si dans des travaux en cours, nous cherchons à évaluer l'ensemble de ces services d'approvisionnement, les enquêtes sur lesquelles se basent cet article se limitent à la production de riz. Le service d'approvisionnement met en évidence la capacité productive de l'agroécosystème. Dans le cas de la riziculture, il peut être approché par la productivité de la terre, c'est-à-dire le rapport entre la valeur ajoutée nette et la superficie. Cet indicateur mesure la part de la terre dans la formation de la valeur ajoutée. L'idée est que plus la productivité est élevée, plus le service d'approvisionnement l'est aussi. La catégorie « services de régulation » regroupe les services qui nous paraissent les plus significatifs, tels que le maintien des habitats et la gestion des crues. Le service habitat permet de prendre en compte la capacité de chaque système de production à maintenir ou non les habitats naturels, y compris la qualité de l'eau comme support de l'habitat d'espèces aquatiques. L'usage d'intrants chimiques, par exemple, réduit ce service en polluant potentiellement ces habitats (eutrophisation et toxicités). Le service de régulation lié aux crues met en avant la capacité de chaque système de production à accroître ou bien réduire les bienfaits retirés par le mouvement de flux et de reflux du TSL. Ainsi, les aménagements hydrauliques, s'ils permettent la production rizicole, ont des conséquences négatives sur le fonctionnement de l'écosystème (changement dans la dynamique alluvionnaire...). La troisième catégorie est celle des services culturels. Ils sont analysés sous l'angle du maintien des paysages traditionnels, reflétant l'identité khmère, de la conservation des traditions associées à des savoirs locaux que l'on peut rapprocher de la notion de patrimoine immatériel, et enfin de la spiritualité liée aux lieux.

Les données ont été collectées dans six villages: Srayov Tbong, Roka et Rolous (issus de la commune de Srayov dans le district de Steung Sen); Phanhagy, Ompus et Porkhav (issus de la commune Tbong Kropeu dans le district de Santuk). Ces données ont été obtenues principalement en 2012 et 2013 ainsi que lors de missions postérieures plus courtes (2015 et 2016). Ces dernières avaient pour objectif de constater d'éventuelles évolutions dont nous parlons dans la partie discussion, et de mieux analyser les services culturels et l'impact des pratiques agricoles sur la biodiversité (espèces vivant dans les rizières) en menant quelques groupes de discussion supplémentaires. L'échantillonnage des agriculteurs a été fait par choix raisonné en fonction de la diversité géographique et physique des terrains, ainsi que des modes d'exploitation du milieu (capital, 
M. Neang et P. Méral : Cah. Agric. 2021, 30, 44

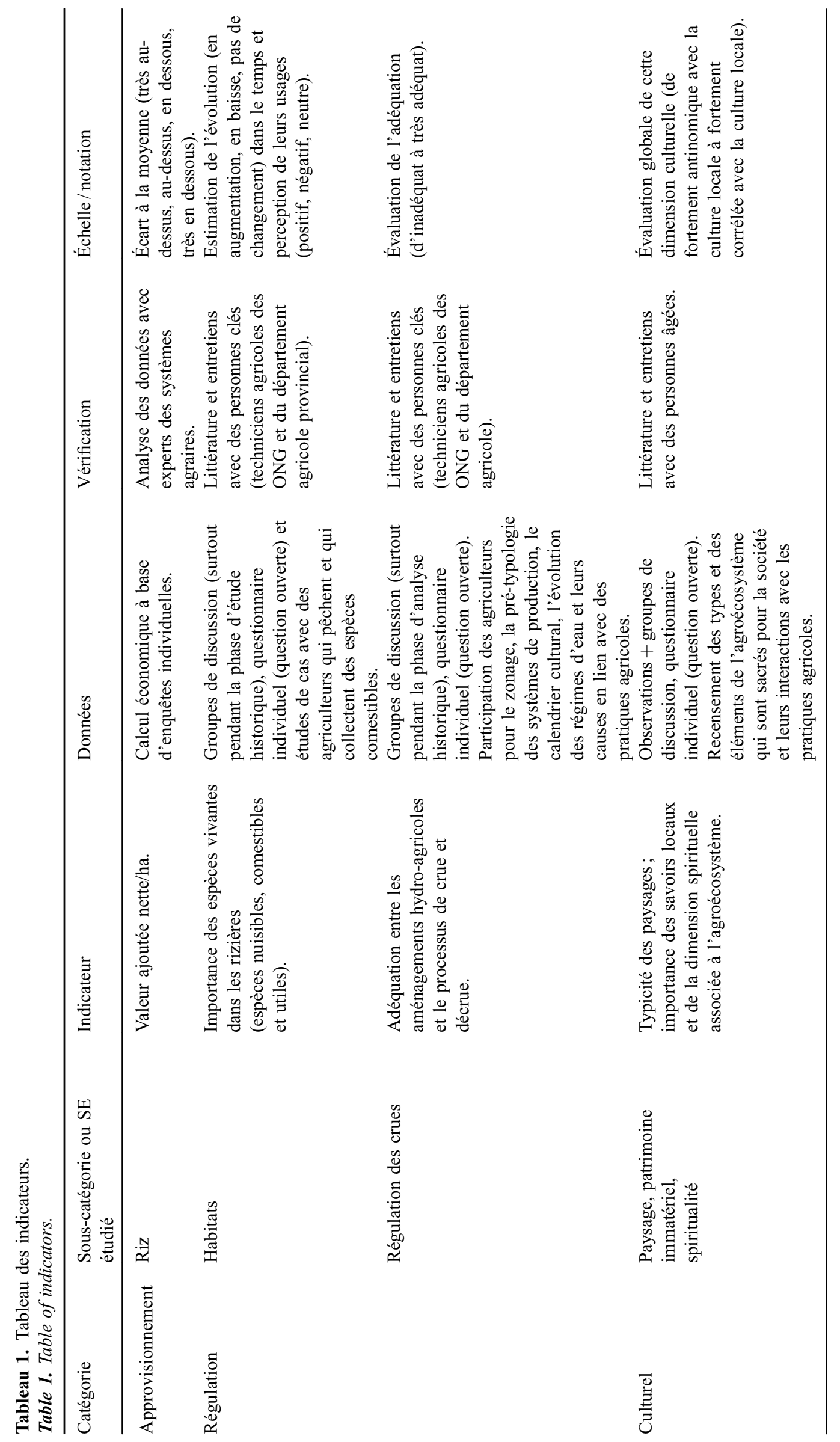

Page 4 de 13 


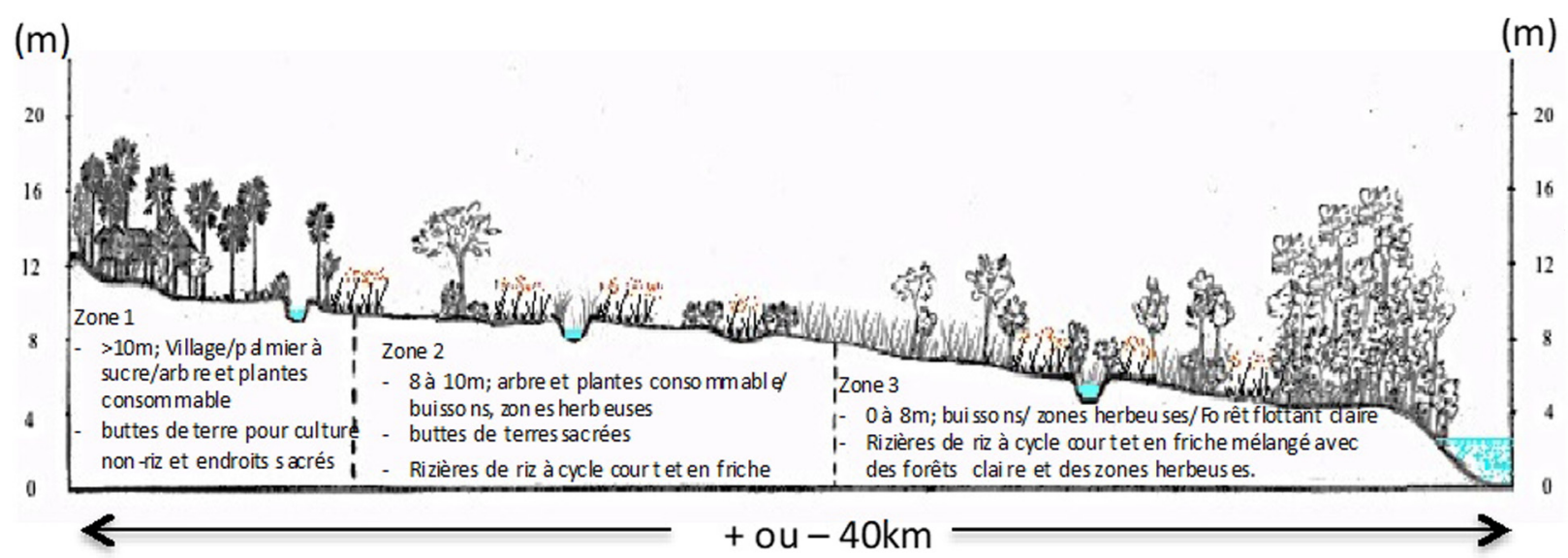

(a)

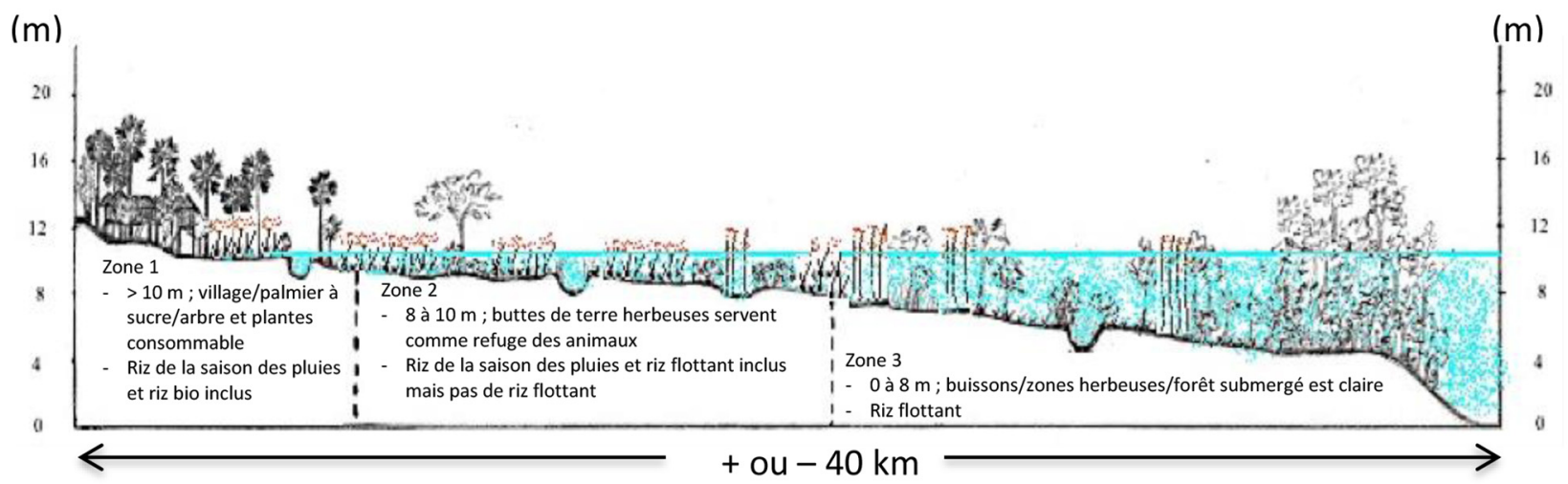

(b)

Fig. 3. Transect de la zone d'étude en saison sèche (a) et en saison des pluies (b).

Fig. 3. Transect of the study zone in dry season (a) and in rainy season (b).

main-d'œuvre, leurs itinéraires techniques et leur aménagement de terrain). Nous avons interrogé au total 208 agriculteurs. Dans un premier temps, nous avons mené 36 entretiens sous forme de groupes de discussion (focus group) ou d'entretiens individuels semi-directifs. Par la suite, 172 agriculteurs ont été interrogés de manière plus approfondie à partir d'un questionnaire fermé afin d'en retirer les éléments nécessaires à la typologie des systèmes de production et au calcul économique. Les traitements de données économiques sous le logiciel SPSS ont permis de retenir 156 agriculteurs pour construire la typologie; les données des 16 agriculteurs restants n'étant pas exploitables.

Puis, un travail de synthèse permettant de mettre en perspective les indicateurs économiques et non économiques a été réalisé. Les résultats qualitatifs obtenus lors des groupes de discussion ont été croisés avec les données issues des entretiens individuels, et de l'observation. Un examen de la littérature technique et scientifique nous a permis de valider certaines données. Seul le service d'approvisionnement a fait l'objet d'un calcul quantitatif. Afin de combiner l'ensemble des données, une notation (relation positive, neutre ou négative, service par service, représentée sous forme de couleur) est affectée à chaque système de production.

\section{Des systèmes de culture adaptés au fonctionnement de l'écosystème}

\subsection{Des dis-services écosystémiques variés selon l'éloignement du lac}

Le site d'étude est localisé dans les plaines inondables lacustres sur la plaine d'épandage alluviale très favorable à la riziculture (Pillot, 2008). Le statut et l'emplacement de la terre, ainsi que la gestion de la main-d'œuvre, déterminent le choix de culture et le niveau de revenus des agriculteurs (Diepart, 2010). Cependant, compte tenu du mouvement du Tonle Sap, les conditions de culture diffèrent selon leur éloignement ou proximité du lac. Ainsi, on distingue trois zones (Fig. 3a et 3b).

La zone 1 se situe approximativement à $10 \mathrm{~m}$ d'altitude. C'est dans cette zone que se trouvent les principaux villages. La période d'inondation est la plus courte des trois zones (d'août à septembre) et dépasse rarement les $30 \mathrm{~cm}$ de crue (Tab. 2). La culture du riz se fait alors à partir de terrains bordés par de petites digues pour retenir l'eau le plus longtemps possible. Plusieurs services écosystémiques sont identifiés : conditions humides pour la culture de riz, habitat pour de nombreuses espèces aquatiques (plantes et animaux) servant d'aliments pour la population locale. Enfin, elle est le lieu où 
Tableau 2. Représentation des différents systèmes rizicoles selon le niveau de l'eau du lac Tonle Sap. Pour les trois zones, les cellules blanches représentent la période de décrue, les cellules bleu clair (autour des mois d'août et de septembre) la période de crue, les cellules bleu foncé les périodes de risque d'inondation (pluies intenses en juin et juillet, début de saison des pluies et crue importante du lac en fin de saison des pluies). Table 2. Presentation of the different rice cropping systems with regard to the water level of Tonle Sap Lake. In each zone, the white cells represent the water recess period, the light blue cells (around August and September) represent the seasonal flood period. The dark blue cells refer to the times of flooding risk (heavy rains in June and July at the start of the rainy season and significant flood disaster at the end of it).

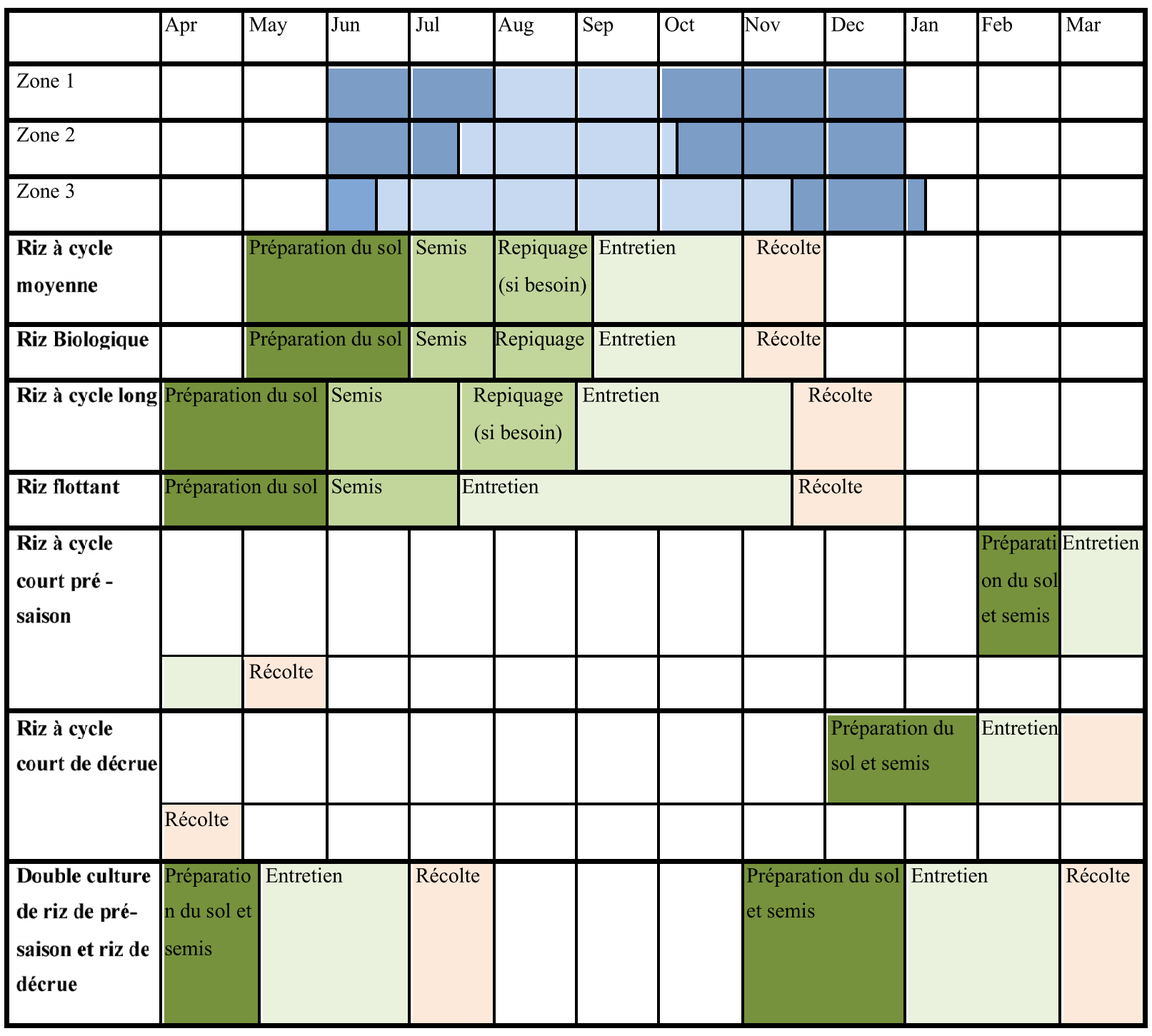

poussent les arbres fruitiers et palmiers à sucre également valorisés par les habitants. Ces palmiers à sucre fournissent plusieurs services écosystémiques : habitat pour les chauvessouris qui régulent les populations d'insectes et contribuent à la fertilité du sol par leurs excréments, production de sucre pour l'alimentation et vecteur de l'identité khmère. Les principales cultures de riz dans cette zone sont les riz de saison des pluies à cycle moyen et à cycle long, ainsi que le riz de pré-saison et un peu de riz de décrue avec les variétés à haut potentiel de rendement. La zone 1 est aussi la seule zone appropriée pour le riz biologique en raison des possibilités offertes en termes d'aménagement contre les inondations, la certification du riz bio imposant une culture pluviale et non inondée (Rambonilaza et Neang, 2019). Pour autant, les dis-services sont également présents dans la zone. L'éloignement du lac rend parfois problématique l'alimentation en eau lors de saisons peu pluvieuses. Il n'est alors pas rare de constater de faibles productions de riz. À l'inverse, les périodes d'inondation créent non seulement des soucis pour la population en termes de déplacement, mais génèrent également la perte du label de riz biologique.

La zone 2, plus proche du lac, se caractérise par une altitude comprise entre 8 et $10 \mathrm{~m}$. Les rizières sont plus profondes que celles de la zone 1. En raison d'une période d'inondation plus longue (mi-juillet jusque fin novembre) et plus intense (15 à $40 \mathrm{~cm}$ ) (Tab. 2), il n'y a pas de cultures arboricoles pérennes. Les champs sont principalement dédiés à la culture du riz tout en servant de terres pastorales pour les 
buffles pendant la friche de la saison sèche. Les terrains inondés sont alors l'habitat privilégié de nombreux animaux aquatiques tels que les rats et les souris, véritables fléaux pour la culture du riz. Ils sont chassés et parfois vendus jusqu'au Vietnam. Ces animaux représentent à la fois un service d'approvisionnement et un dis-service pour la production de riz. Dans cette zone, les agriculteurs produisent essentiellement du riz de saison des pluies à cycle long, une double culture de riz à haut potentiel de rendement (en riz de présaison et en riz de décrue) et un peu de riz flottant dans des lacs et des zones de bas fonds.

La zone 3 est située au plus proche du lit du LTS (inférieur à $8 \mathrm{~m}$ d'altitude). De ce fait, le riz cultivé est essentiellement du riz flottant et la particularité de la zone est d'être riche en forêt inondée, pourvoyeuse de bois (énergie et construction), miel et plantes médicinales. L'habitat pour les poissons y est également plus favorable qu'ailleurs, ce qui conduit à des systèmes de production associant culture de riz flottant, pêche et produits forestiers ligneux et non ligneux. Là encore, les rats offrent une opportunité commerciale. Les rats d'eau, considérés comme plus sains, sont très appréciés des consommateurs alors qu'ils restent nuisibles du fait de leurs dégâts sur les cultures. Cependant, la tendance actuelle est au renoncement à l'exploitation de ce riz flottant car il n'est produit qu'en saison des pluies. À l'inverse, en raison des techniques d'irrigation ou de retenue d'eau, les productions dans les autres zones ou dans les zones aménagées privilégient le riz de décrue, voire la double culture avec des variétés sélectionnées à haut potentiel de rendement.

Finalement, le mouvement de crue et de décrue du Tonle Sap développe un écosystème complexe qui génère une série de services écosystémiques et de dis-services, distincts selon la proximité avec le lac. Parfois le passage de service à disservice est fréquent. Un flux d'eau trop important peut créer des inondations et ce qui est au départ un service devient (momentanément) un dis-service.

\subsection{Des services écosystémiques co-produits}

Ainsi, si la riziculture contribue aux services d'approvisionnement, elle co-produit d'autres types de services. C'est le cas des services culturels à travers les paysages agricoles façonnés par ces pratiques et qui contribuent à l'identité khmère. De même, ces pratiques peuvent selon les cas être compatibles avec la régulation des crues ou au contraire perturber le cycle de l'eau; elles peuvent contribuer à maintenir les habitats ou au contraire les perturber. Ces effets créent une boucle rétroactive sur l'écosystème, si bien qu'en dynamique la population locale bénéfice de services (ou est victime de dis-services) de l'agroécosystème en question. Il est alors possible de présenter l'agroécosystème rizicole selon le cadre d'analyse de Swinton et al. (2007) (Fig. 4).

\section{Typologie d'exploitations}

En suivant les principes de l'analyse des systèmes agraires, nous avons élaboré une typologie des exploitations qui tient compte de critères tels que la superficie agricole, le capital investi, le revenu dégagé par les exploitations et la quantité de travail (Neang et al., 2017). Au regard de ces critères, on peut ainsi identifier deux grandes catégories de systèmes de production.

Un premier groupe d'exploitations rassemble les agriculteurs qui ont une pratique que l'on peut qualifier d' «intensive », avec le recours à la mécanisation (pour l'irrigation et/ou pour la culture elle-même) et aux intrants chimiques, ce qui se traduit par des surfaces cultivées relativement importantes au regard des conditions locales. Cette catégorie, qui représente un tiers de l'effectif étudié, s'inscrit dans une logique productiviste. Au sein de cette catégorie, on peut toutefois distinguer deux groupes. D'un côté, un type A regroupe les paysans qui cultivent essentiellement des riz de variétés sélectionnées à haut potentiel de rendement, à cycle court et non photopériodiques (en combinant parfois avec le riz de pré-saison des pluies et le riz de décrue). Le type B rassemble les agriculteurs qui combinent plusieurs types de culture, notamment des riz à cycle court avec des riz de saison des pluies, voire dans certains cas avec du riz flottant.

La deuxième catégorie rassemble tous les autres exploitants. Ils partagent quelques caractéristiques communes : petite superficie d'1 à 2,5 ha environ, absence de mécanisation, combinaison de systèmes de culture moins complexe (maximum deux) et revenus agricoles plus faibles. Nous distinguons trois profils d'exploitations au sein de cette seconde catégorie. Le type $\mathrm{C}$ regroupe ceux qui adoptent partiellement ou totalement le cahier des charges de la culture de riz certifié biologique (14\%) avec des variétés sélectionnées semi-photopériodiques à cycle moyen. Le type D est composé des agriculteurs qui adoptent une culture de riz de saison des pluies à cycle moyen ou long, appelé aussi riz traditionnel (24\%) au regard de pratiques anciennes ; et enfin le type E, qui recourt exclusivement au riz flottant (27\%). L'ensemble de ces données est synthétisé dans le tableau 3.

\section{Typologie d'exploitations et services écosystémiques: des résultats significatifs}

De manière synthétique, on peut représenter les tendances de chaque système de production au regard des services écosystémiques identifiés et analysés à l'aide des indicateurs présentés plus haut (Tab. 1). Le tableau 4 propose une représentation globale et didactique des relations entre systèmes de production et services et dis-services écosystémiques.

\subsection{Des pratiques rizicoles impactantes}

Les types d'exploitation qui fournissent le plus de services d'approvisionnement à l'hectare sont ceux qui sont de grande taille et qui adoptent une double culture de riz ou une seule culture annuelle de riz à cycle court dans des rizières aménagées pour l'irrigation et la mécanisation. Toutefois, les revenus les plus élevés dégagés par la production de riz sont jugés par les producteurs comme peu performants au regard des autres services de régulation et dans une certaine mesure du service culturel. C'est par exemple le cas du riz à cycle court de pré-saison et de décrue, voire de la double culture des deux. Grâce à des rendements 


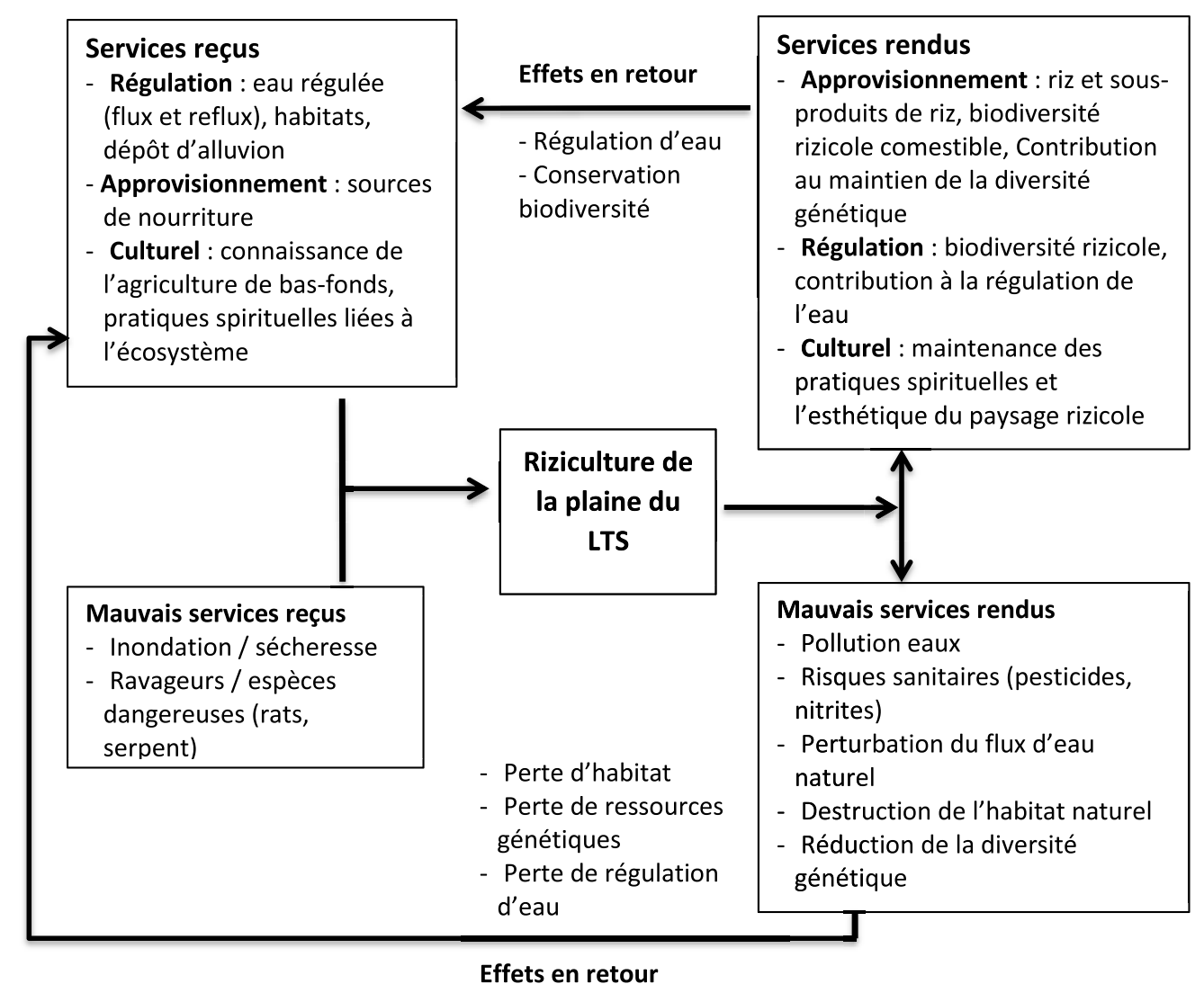

Fig. 4. Adaption de la figure 2 au contexte de l'étude.

Fig. 4. Adaptation of Figure 2 to the study's context.

élevés et en dépit de coûts liés à l'achat d'intrants, ce type de culture permet une forte productivité de la terre, mais au détriment des principaux services de régulation en raison d'une forte utilisation de pesticides. Ainsi, le terme de « cocktail de pesticides » (au moins 3 pesticides mélangés) est souvent utilisé pour qualifier cet usage. Une étude récente menée par Bureau-Point et Doeurn (2019) montre à quel point l'usage intensif de pesticides fait perdre confiance dans les produits agricoles, non seulement auprès des consommateurs, mais aussi chez les agriculteurs eux-mêmes. Cette situation est d'ailleurs préoccupante, dans la mesure où $75 \%$ des personnes interrogées lors de nos entretiens individuels considèrent comme impropres à la consommation les poissons et les plantes issus des rizières du riz à cycle court et des canaux d'irrigation, en raison même de l'abondance des pesticides utilisés dans cette riziculture.

À l'inverse, les systèmes de production les plus compatibles avec la fourniture de ces services de régulation (habitat pour les catégories $\mathrm{C}, \mathrm{D}$ et $\mathrm{E}$; voire la régulation des crues pour le riz flottant) sont moins performants économiquement. On constate également que les systèmes les plus performants sur le plan de la fourniture des services de régulation et culturels sont plutôt des exploitations de petite taille et faiblement mécanisées qui font très peu d'aménagements de terrain; au contraire, ils s'adaptent aux flux d'eau naturels tout en préservant la végétation naturelle.

\subsection{Les services culturels varient peu selon les systèmes de production}

Les services culturels identifiés dans la zone d'étude sont de trois ordres. Premièrement, ils concernent l'esthétique du paysage agricole typique du Cambodge. Les aménagements de l'agroécosystème, représentés par des rizières, des diguettes et des palmiers à sucre, participent à la constitution d'un patrimoine culturel, du sentiment d'appartenance à la culture khmère, etc. Deuxièmement, des savoirs locaux liés à l'utilisation de ces palmiers sont également associés à cet agroécosystème (la production de jus et de sucre, l'utilisation des feuilles pour entourer différents types de gâteaux, l'élevage et la collecte des excréments de chauve-souris pour en faire de l'engrais, la fabrication de pirogues avec les troncs de palmiers, etc.). Troisièmement, l'agroécosystème renferme des croyances liées à la présence de termitières. Ces termitières représenteraient des hôtes pour des esprits puissants, qui peuvent être à la fois protecteurs ou destructeurs selon le respect que les populations locales leur portent. Des prières se font souvent en cas de catastrophe naturelle (sécheresse, inondation, ravages d'insectes, etc.). Une fois par an, les propriétaires des rizières où se trouvent ces termitières font des prières avec de nombreuses offrandes, avant de les casser (à peu près de moitié), de les broyer et de les répandre sur les sols prêts à être labourés. 
Tableau 3. Données économiques des systèmes de production.

Table 3. Economic data of production systems.

\begin{tabular}{|c|c|c|c|c|c|c|c|}
\hline \multirow{2}{*}{$\begin{array}{c}\text { Nombre } \\
\text { d'agriculteurs } \\
(156)\end{array}$} & \multirow{2}{*}{ Type de production de riz } & \multirow{2}{*}{$\begin{array}{c}\text { Surface } \\
\text { moyenne par } \\
\text { exploitation }\end{array}$} & \multirow{2}{*}{$\begin{array}{c}\text { Rendement } \\
\text { (tonnes de } \\
\text { riz à } \\
\text { l'hectare) }\end{array}$} & \multirow{2}{*}{$\begin{array}{c}\text { Travail (ETP } \\
\text { annuel) }\end{array}$} & \multicolumn{2}{|c|}{ Capital technique } & \multirow{2}{*}{$\begin{array}{c}\text { Valeur } \\
\text { ajoutée nette } \\
\text { à l'hectare } \\
\text { (en USD) }\end{array}$} \\
\hline & & & & & Motoculteur & Pompe & \\
\hline \multirow{13}{*}{$55(35 \%)$} & \multicolumn{7}{|l|}{ A. Système intensif (fort) } \\
\hline & A1. Double riz pré-sais on et riz de décrue & 5,0 & 9,1 & 3,5 & oui & oui & 675 \\
\hline & A2. Double riz pré-sais on et riz de décrue + Riz de décrue & 5,3 & 6,8 & 3,5 & oui & oui & 484 \\
\hline & A3. Riz de décrue & 5,0 & 4,6 & 3,5 & oui & non & 275 \\
\hline & \multicolumn{7}{|l|}{ B.Système intensif (modéré) } \\
\hline & B1. Double riz pré-sais on et riz de décrue + Riz de décrue + Riz flottant & 7,9 & 5,9 & 3,5 & oui & oui & 468 \\
\hline & B2. Riz de décrue + Riz moyen terme repiqué+ Riz long terme semé direct & 8,9 & 3,6 & 3,5 & oui & oui & 352 \\
\hline & B3. Riz pré-sais on + Riz de décrue +Riz long terme repiqué & 8,3 & 4,7 & 3,5 & oui & oui & 388 \\
\hline & B4. Riz de décrue + Riz moyen terme semé direct + Riz flottant & 3,6 & 2,6 & 2,5 & non & oui & 208 \\
\hline & B5. Double riz pré-saison et riz de décrue + Riz moyen terme semé direct & 1,6 & 7,0 & 2,5 & non & oui & 589 \\
\hline & B6. Double riz pré-sais on et riz de décrue + Riz moyen terme semé direct + Riz flottant & 2,7 & 3,6 & 3,0 & oui & oui & 227 \\
\hline & B7. Riz pré-saison + Riz flottant & 2,1 & 6,1 & 3,5 & non & oui & 451 \\
\hline & B8. Riz de décrue + Riz flottant & 3,0 & 3,1 & 3,0 & non & oui & 236 \\
\hline \multirow{4}{*}{$22(14 \%)$} & \multicolumn{7}{|l|}{ C. Système de riz biologique } \\
\hline & C1. Riz biologique + Riz long terme semé direct & 1,5 & 1,5 & 2,0 & non & non & 315 \\
\hline & C2. Riz biologique & 0,8 & 2,2 & 2,5 & non & non & 406 \\
\hline & C3. Riz biologique + Riz flottant & 1,3 & 1,5 & 2,5 & non & non & 193 \\
\hline \multirow{5}{*}{$37(24 \%)$} & \multicolumn{7}{|l|}{ D. Système traditionnel } \\
\hline & D1. Riz moyen terme semé direct + Riz flottant & 2,4 & 1,5 & 4,0 & non & non & 189 \\
\hline & D2. Riz long terme semé direct & 1,2 & 1,3 & 3,0 & non & non & 190 \\
\hline & D3. Riz moyen terme repiqué + Riz moyen terme semé direct & 1,2 & 1,5 & 2,5 & non & non & 188 \\
\hline & D4. Riz long terme semé direct + Riz flottant & 0,9 & 1,5 & 3,0 & non & non & 136 \\
\hline \multirow{2}{*}{$42(27 \%)$} & \multicolumn{7}{|l|}{ E. Système de riz flottant } \\
\hline & E1. Riz flottant & 1,3 & 1,6 & 1,5 & non & non & 160 \\
\hline
\end{tabular}

Tableau 4. Liens entre systèmes de production et services et dis-services écosystémiques.

Table 4. Links between production systems and ecosystem services and dis-services.

\begin{tabular}{|c|c|c|c|c|c|}
\hline \multirow{2}{*}{\multicolumn{2}{|c|}{$\begin{array}{l}\text { Modèle de système de } \\
\text { production }\end{array}$}} & \multirow{2}{*}{$\begin{array}{c}\text { Service } \\
\text { d'approvision } \\
\text {-nement (riz) }\end{array}$} & \multicolumn{2}{|c|}{ Services de régulation } & \multirow{3}{*}{$\begin{array}{l}\text { Service } \\
\text { culturel }\end{array}$} \\
\hline & & & Habitat & Crues & \\
\hline A & $\begin{array}{l}\text { Système intensif } \\
\text { (fort) }\end{array}$ & & & & \\
\hline B & $\begin{array}{l}\text { Système intensif } \\
\text { (modéré) }\end{array}$ & & & & \\
\hline C & Système biologique & & & & \\
\hline $\mathrm{D}$ & $\begin{array}{l}\text { Système } \\
\text { traditionnel }\end{array}$ & & & & \\
\hline$E$ & Système riz flottant & & & & \\
\hline
\end{tabular}

Une flèche montante et verte représente une relation globalement positive. Une flèche descendante et rouge représente une relation négative. Une flèche droite et bleue indique une relation neutre.

A green upward arrow represents an overall positive relationship. A red downward arrow represents a negative relationship. A straight blue arrow indicates a neutral relationship. 
Le constat que nous retirons de notre analyse est que la dimension culturelle est peu dépendante du système de production. Nos enquêtes montrent que même les producteurs de riz à cycle court, c'est-à-dire ceux qui recourent aux machines et aux intrants chimiques, respectent ces traditions et ces usages.

\subsection{La régulation des crues est un enjeu pour la plupart des systèmes de production}

Le service de régulation lié aux crues est le plus évident compte tenu des liens avec le LTS. Rappelons d'ailleurs que la rizière en général (Srè) signifie en cambodgien «des terrains inondables favorables pour le riz», et renvoie généralement indirectement à la plaine inondable du LTS. Au contraire, les rizières de riz pluvial s'appellent Chamkar, qui renvoie à la notion de terrain «hors de zone inondable» et couvre toute forme de culture pluviale. C'est la gestion du mouvement de crue et de décrue qui détermine la localisation des rizières et le type de culture associé. Mais les systèmes rizicoles n'ont pas les mêmes interactions avec ce cycle de l'eau; notamment dans la zone 3, là où l'eau arrive en premier et repart en dernier. En effet, les cultures de riz flottant par exemple n'ont que peu d'impact sur cette circulation et sont parfaitement adaptées à différents niveaux d'eau. Ce type de culture ne nécessite pas d'aménagement particulier. Il laisse ainsi les arbres sur pied, ce qui permet de maintenir des sols humides en saison sèche (Fig. 5). À l'inverse, les autres systèmes reposent sur une maîtrise plus ou moins forte de cette circulation de l'eau à travers des canaux d'irrigation, des réservoirs, etc., qui impactent en retour la circulation globale de l'eau (Fig. 6). En présence de systèmes d'irrigation combinant des réservoirs, des canaux entourés par des digues d'un à trois mètres de haut, l'arrivée de l'eau est ralentie au début de la saison des pluies, ce qui impacte le début de la production. La décrue, qui est également ralentie en fin de la saison, peut causer la perte des récoltes en raison des apports alluvionnaires, la terre boueuse retardant la récolte. Cela ralentit aussi le début du riz de décrue par manque d'eau à la fin du cycle. Enfin, dans le cas de crues fortes, les cultures peuvent être détruites si l'eau ne se retire pas assez vite. Les aménagements récents, de type intensif à grande échelle, modifient cette dynamique et peuvent avoir à terme des effets importants sur ce service de régulation des crues.

\subsection{Des différences fortes pour le service habitat}

En raison du statut de «réserve de biosphère» de l'UNESCO, les inventaires de biodiversité au sein du LTS sont nombreux et bien documentés. Mais ils concernent essentiellement les zones non agricoles du LTS. Aussi, c'est à travers nos enquêtes que nous avons pu recenser de nombreuses espèces présentes dans les agroécosystèmes: petits poissons (silure, perche, poisson chat...), gros poissons (poisson au bec gar, différents types de poisson tête de serpent et de poisson chat...), plantes aquatiques (liseron d'eau, nénuphar, rhizome de lotus, jacinthe d'eau...), escargots, crabes, coquillages, petites crevettes d'eau douce, serpents, anguilles, rats et souris, grenouilles principalement. Ces espèces sont source de revenus significatifs pour les populations (Balzer et al., 2002). Pour autant, le type de système de production au sein de ces agroécosystèmes a une influence forte sur les services de régulation qui concernent l'habitat des espèces vivantes. En effet, de nombreuses espèces vivent dans ces rizières, mais on les trouve essentiellement dans les espaces peu impactés par la présence d'intrants chimiques. Les enquêtes effectuées (notamment via les groupes de discussion) montrent qu'il existe des savoirs locaux associés à cette agrobiodiversité. Ils s'expriment essentiellement à travers l'apport en nourriture (auto-consommation et vente) procuré par ces espèces. Par exemple, le mot «Srè » est devenu l'adjectif pour cette biodiversité collectée, très recherchée pour son goût et pour l'absence de produit chimique. La population pêche et collecte essentiellement dans des rizières de riz flottant et de riz de saison des pluies, ainsi que dans les lacs naturels et certains canaux d'irrigation, mais peu dans des rizières de riz à cycle court par peur d'être empoisonnée. Selon les agriculteurs, les grenouilles et les sangsues n'existent plus dans les rizières de riz à cycle court à cause de l'utilisation de pesticides; et les plantes aquatiques ainsi que les herbes pouvant servir de fourrage n'existent plus non plus à cause de l'utilisation d'herbicides. Les arbres (hors palmier) sont également un facteur important de la présence d'espèces d'oiseaux, ce que l'on trouve plus rarement dans les systèmes intensifs. On notera enfin que les relations entre habitat et culture de riz sont parfois complexes. C'est le cas des rongeurs qui se nourrissent de riz, notamment durant la saison sèche. Pour autant, les rats ne sont pas tués mais attrapés pour être vendus. Il existe ainsi un commerce vers le Vietnam dont la population apprécie ces rats cambodgiens. Les liens entre agroécosystème et biodiversité sont donc parfois plus complexes qu'il n'y paraît.

\section{Discussion}

Les éléments d'analyse proposés précédemment montrent une tendance à l'intensification de la riziculture au détriment des services de régulation, tout en ayant un impact modéré sur les services culturels. Il s'agit là d'une évolution qui s'inscrit dans le temps long et fortement marquée par l'histoire du pays. Ainsi, il importe de préciser que les années postérieures au conflit des Khmers rouges (début des années 1980) ont été marquées à la fois par une pénurie de riz liée à de faibles moyens de production (semences, matériels, moyens humains...) et par une conversion progressive vers l'économie de marché, tranchant avec les politiques menées jusqu'alors (Pillot, 2008). Au début de la présence vietnamienne (19791989), les terres de culture ont été collectivisées (krom samaki), puis progressivement attribuées aux exploitants individuels, essentiellement en zone 1 et 2 (la zone 3 étant un lieu de refuge d'anciens khmers rouges où les paysans défrichaient pour en faire du riz flottant). Les superficies exploitées par famille étaient d'assez petite taille (autour de 2 ha, voire 5 lorsque la densité était faible), ce qui explique bien la situation constatée dans nos villages étudiés. Les disparités entre riziculteurs étaient également liées à des situations de rente où les personnes les plus proches de l'administration profitaient de leur pouvoir local pour s'accaparer de plus grandes superficies (Diepart, 2015). De même, le fait de posséder du cheptel dès la fin de la guerre a permis à certains non seulement de bénéficier de l'octroi de davantage de terres par l'administration, mais aussi d'accroître les superficies exploitées, notamment celles pour le riz flottant qui est une culture extensive, nécessitant peu de travail, mais 


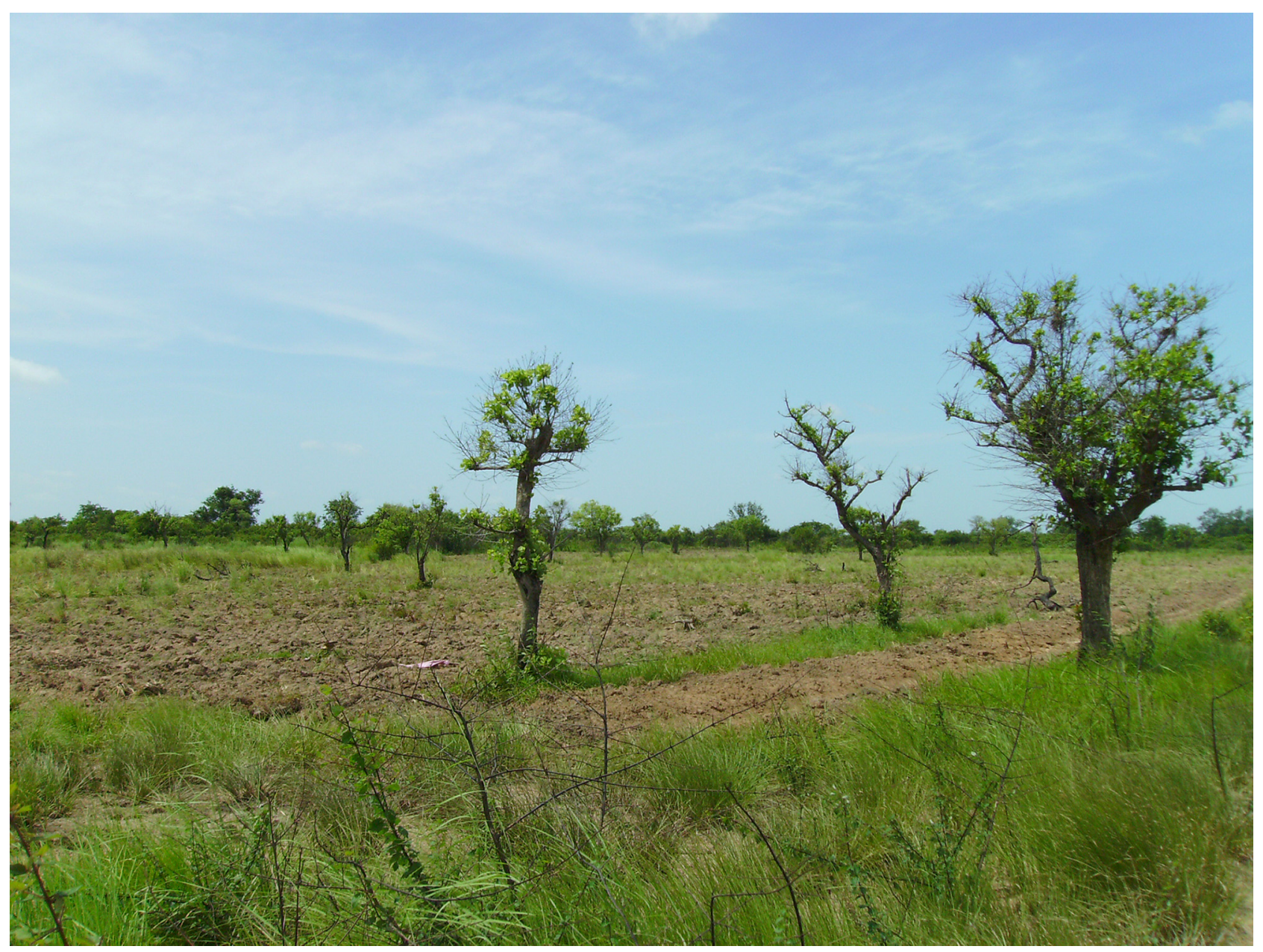

Fig. 5. Rizières extensives de riz flottant où les agriculteurs produisent en harmonie avec des arbres de forêt inondée.

Fig. 5. Extensive floating rice fields where farmers produce in harmony with flooded forest trees.

de la maitrise foncière (apportée plus facilement par l'utilisation de bœufs).

Au fil du temps, les paysans bénéficiant de cheptels et de surfaces en riz flottant ont progressivement développé la riziculture sur des terres plus éloignées du lac, et donc moins risquées vis-à-vis des crues extraordinaires. Certains y ont développé la riziculture biologique. Le cheptel a été vendu au profit de motopompes et de motoculteurs, le type de culture s'est orienté vers le riz irrigué de pré-saison et de décrue avec des variétés à haut potentiel de rendement très gourmandes en intrants. Cette évolution, caractérisant les systèmes A et B de notre typologie (Tab. 3), s'est également manifestée par un endettement auprès des commerçants d'intrants chimiques. À l'inverse, les paysans peu dotés en bovins sont restés dans une situation de faibles revenus, d'emprunts durant la période de soudure et de salariat auprès des plus grands exploitants. Ils ont souvent une double activité économique. Ils produisent du riz flottant (système E), ce qui demande peu de travail, tout en se salariant pour des tâches agricoles pendant la saison des pluies et de constructions en ville durant la saison sèche. D'autres continuent de produire les riz de la saison des pluies dits traditionnels (système $\mathrm{D}$ ) pour l'autosuffisance. Les systèmes intensifs (A et B) se sont donc étendus et consolidés au détriment des systèmes $\mathrm{C}, \mathrm{D}$ et $\mathrm{E}$.
Cette politique d'exportation du riz encouragée par l'État a conduit à une plus grande intensification des cultures avec le recours à des intrants chimiques et des pesticides. De même, l'État a favorisé l'emploi de nouvelles variétés sélectionnées plus adaptées à ces objectifs d'exportation, mais parfois au détriment de la qualité des riz produits. Cette situation est rendue complexe par le soutien à la production et l'exportation de riz parfumé, voire de riz biologique. La certification du riz biologique s'est réalisée au début des années 2000 avec le soutien de bailleurs internationaux (Allemagne notamment), permettant de faire émerger les agriculteurs issus du groupe C. Cela s'est traduit par l'adoption de certaines pratiques et la structuration de la filière autour d'une association dédiée (Raksmey Stung Sen Association). Toutefois, l'adoption et le maintien de la certification «riz biologique » nécessitent une structuration de la filière pérenne et adaptée, ce qui n'est pas toujours le cas. Ainsi, en 2015, le décès du président de cette association a complètement déstabilisé la filière locale; les agriculteurs ont continué à produire du riz biologique, mais en le vendant au même prix (plus bas) que le riz conventionnel. En dépit d'une demande pour ce riz biologique, même à l'échelle nationale (dans les villes par exemple), l'avenir de cette filière est fragile (Rambonilaza et Neang, 2019). 


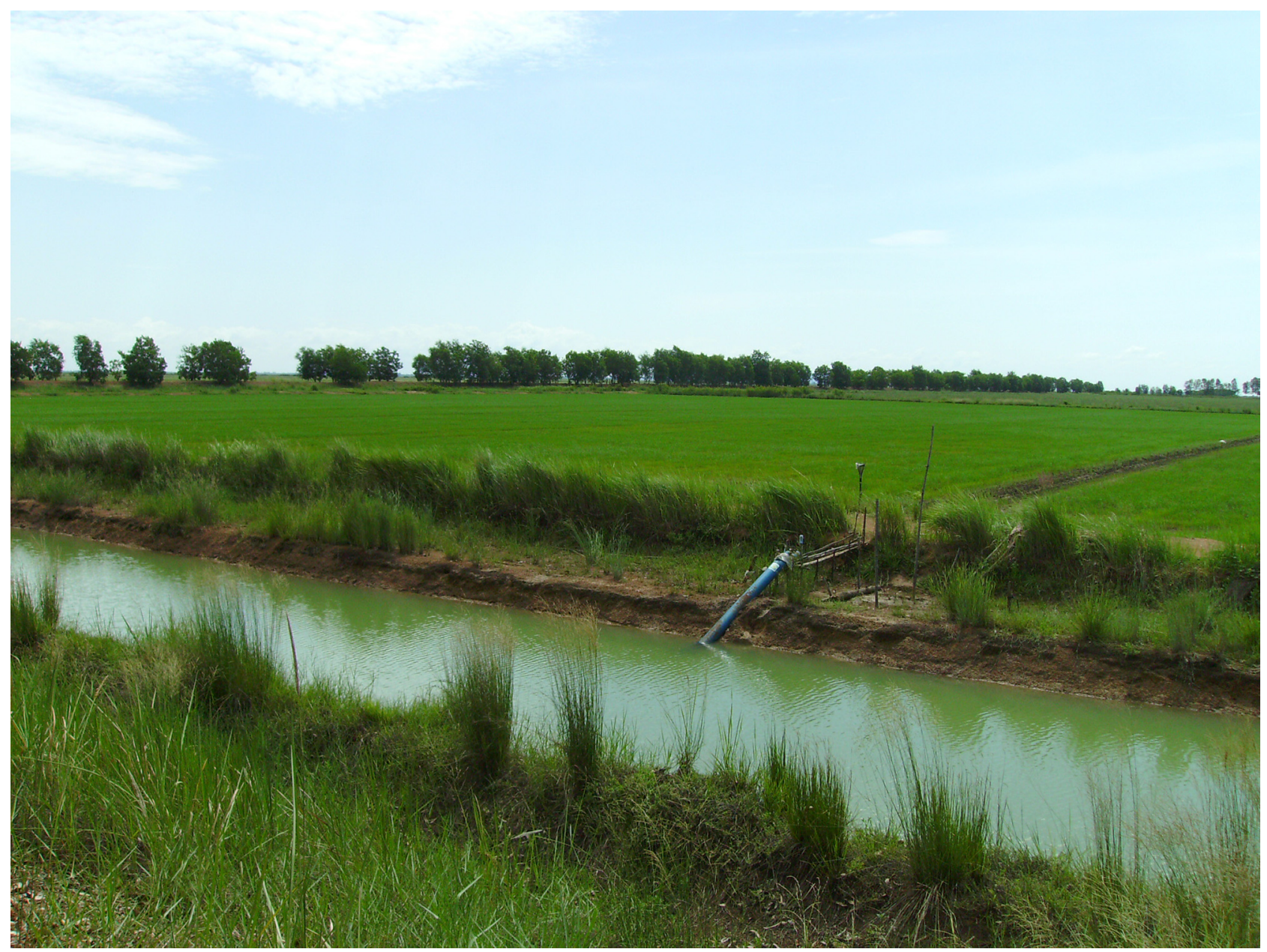

Fig. 6. Rizières intensives de riz à cycle court.

Fig. 6. Intensive short-cycle rice fields.

Des travaux récents, portant sur d'autres communes à proximité de Battambang, nous ont permis de consolider ces tendances (Sok et al., 2019): l'existence d'un gradient de catégories de paysans depuis la zone 3 vers la zone 1 , mobilisant des pratiques rizicoles plus ou moins intensives adossées à des revenus plus forts au fur et à mesure de l'éloignement du lac. La prise en compte d'autres activités pour intégrer la pluriactivité et la multifonctionnalité de l'écosystème ne changent fondamentalement pas ce constat. Là où les paysans proches de la zone 3 combinent riziculture et pêche, ceux de la zone 1 associent plutôt riziculture, élevage et activités non agricoles (commerce près des routes, fonction dans l'administration, etc.); ces dernières activités étant à la fois plus rémunératrices et sources de capital social. D'autres auteurs qui n'adoptent pas le cadre des systèmes agraires concluent également à la vulnérabilité des ménages vivant au plus proche du LTS; vulnérabilité dont il faudrait davantage tenir compte dans un contexte de changement climatique (Marschke et Berkes, 2006; Nuorteva et al., 2010).

\section{Conclusion}

Si le Cambodge prône l'intensification de la riziculture avec les effets que nous venons de mettre en évidence tant sur l'écosystème du lac Tonle Sap que sur les pratiques paysannes, d'autres dynamiques économiques et institutionnelles viennent complexifier l'analyse et plaident pour une meilleure prise en compte des différents niveaux de régulation. Ainsi, d'un côté, les bailleurs de fonds et les Organisations non gouvernementales de conservation agissent le sens d'une meilleure conservation et mise en valeur de ce patrimoine naturel et culturel en soutenant différents programmes, particulièrement pour la protection de la zone la plus proche du lac et des communautés vivant dans les villages flottants, comme par exemple le maintien de la production de riz flottant, l'introduction de l'agroécologie et l'écotourisme. Le statut de réserve de biosphère attribué par l'UNESCO en 1997 témoigne de l'intérêt de la communauté internationale pour la conservation de cet écosystème (Keskinen et Varis, 2012) et pour la culture de riz de bas fond qui s'adapte à merveille à l'inondation sans besoin de modifier l'écosystème naturel et qui préserve en même temps l'habitat pour les espèces aquatiques et terrestres de cet agroécosystème. Mais par ailleurs, la construction de barrages en amont (à des fins hydroélectriques), notamment en Chine, laisse présager d'une évolution peu propice au maintien des fonctionnalités de l'écosystème du lac Tonle Sap, et par conséquent à l'agriculture paysanne. Il convient donc d'avoir à l'esprit 
que les enjeux de gouvernance et les arbitrages entre services écosystémiques, à l'échelle du lac Tonle Sap, voire du pays tout entier, sont complexes à saisir.

\section{Références}

ADB. 2005. Summary initial environmental examination report for Tonle Sap sustainable livelihood project in Cambodia. Manila (The Philippines): Asian Development Bank (ADB), $36 \mathrm{p}$.

Arias ME, Cochrane TA, Piman T, Kummu M, Caruso BS, Killeen TJ. 2012. Quantifying changes in flooding and habitats in the Tonle Sap Lake (Cambodia) caused by water infrastructure development and climate change in the Mekong Basin. Journal of Environmental Management 112: 53-66. https://doi.org/10.1016/j.jenvman.2012.07.003.

Balzer T, Balzer P, Pon S. 2002. Traditional use and availability of aquatic biodiversity in rice-based ecosystems: I. Kampong Thom Province, Kingdom of Cambodia. Halwart M, Bertley D, Guttman $\mathrm{H}$, eds. Rome (Italy): FAO, $17 \mathrm{p}$.

Baran E, Myschowoda C. 2008. Have fish catches been declining in the Mekong River Basin? In: Kummu M, Keskinen M, Varis O, eds. Modern Myths of the Mekong. Water \& Development PublicationHelsinki University of Technology, pp. 55-64.

Bonin M, Eloy L. 2014. Services écosystémiques et agriculture. Repères pour l'action, Fiche 10. http://www.serena-anr.org/ FICHES REPERE POUR L ACTION.HTM.

Brooks SE, Allison EH, Reynolds JD. 2007. Vulnerability of Cambodian water snakes: Initial assessment of the impact of hunting at Tonle Sap Lake. Biological Conservation 139(3-4): 401-414. https://doi.org/10.1016/j.biocon.2007.07.009.

Bureau-Point E, Doeurn S. 2019. Substances chimiques et peurs alimentaires au Cambodge. Moussons 34: 109-140. https://doi.org/ 10.4000/moussons.5417.

Cochet H. 2012. The systeme agraire concept in francophone peasant studies. Geoforum 43(1): 128-136. https://doi.org/10.1016/j.geo forum.2011.04.002.

Cochet H, Devienne S. 2006. Fonctionnement et performances économiques des systèmes de production agricole : une démarche à l'échelle régionale. Cahiers Agricultures 15(6): 578-583. https:// doi.org/10.1684/agr.2006.0028.

Cochet H, Devienne S, Dufumier M. 2007. L'agriculture comparée, une discipline de synthèse ? Économie rurale (297-298): 99-112. https://doi.org/10.4000/economierurale.2043.

Dan P, Gordon C, Sok SI. 2005. Long-term rates of sediment accumulation in the Tonle Sap, Cambodia: A threat to ecosystem health? Journal of Paleolimnology 33(1): 95-103. https://doi.org/ 10.1007/s10933-004-1323-2.

Diepart JC. 2010. Cambodian peasant's contribution to rural development: A perspective from Kampong Thom Province. Biotechnologie Agronomie Société et Environnement 14(2): 321-340.

Diepart JC. 2015. The fragmentation of land tenure systems in Cambodia: Peasants and the formalization of land rights. Country profile $n^{\circ} \%$ : Cambodia. France: GRET, AgroParisTech, AGTER, 36 p.

Hai PT, Masumoto T, Shimizu K. 2008. Development of a twodimensional finite element model for inundation processes in the
Tonle Sap and its environs. Hydrological Processes 22(9): 1329 1336. https://doi.org/10.1002/hyp.6942.

Keskinen M, Varis O. 2012. Institutional cooperation at a basin level: For what, by whom? Lessons learned from Cambodia's Tonle Sap Lake. Natural Resources Forum 36(1): 50-60. https://doi.org/ 10.1111/j.1477-8947.2012.01445.x.

Marschke MJ, Berkes F. 2006. Exploring strategies that build livelihood resilience: A case from Cambodia. Ecology and Society 11(1): 42. https://doi.org/10.5751/ES-01730-110142.

Mazoyer M, Roudart L. 1997. Pourquoi une théorie des systèmes agraires? Cahiers Agricultures 6(6): 591-595.

MEA. 2003. Les écosystèmes et le bien-être de l'Homme : un cadre d'évaluation. Washington DC (USA): Island Press, $212 \mathrm{p}$.

Neang M, Meral P, Aznar O, Déprés C. 2017. Diversity of rice cropping systems and organic rice adoption in agro-ecosystem with high risk of flood in Cambodia. Journal of Agricultural Resources, Governance and Ecology 13(4): 351-370. https://doi.org/10.1504/ IJARGE.2017.088402.

Nuorteva P, Keskinen M, Varis O. 2010. Water, livelihoods and climate change adaptation in the Tonle Sap Lake area, Cambodia: Learning from the past to understand the future. Journal of Water and Climate Change 1(1): 87-101. https://doi.org/10.2166/ wcc.2010.010.

Pillot D. 2008. Jardins et rizières du Cambodge: les enjeux du développement agricole. Paris (France) : Editions Karthala, 528 p.

Power AG. 2010. Ecosystem services and agriculture: Tradeoffs and synergies. Philosophical Transactions of the Royal Society B: Biological Sciences 365(1554): 2959-2971. https://doi.org/ 10.1098/rstb.2010.0143.

Rambonilaza T, Neang M. 2019. Exploring the potential of local market in remunerating water ecosystem services in Cambodia: An application for endogenous attribute non-attendance modelling. Water Resources and Economics 25: 14-26. https://doi.org/ 10.1016/j.wre.2018.07.001.

Sok K, Méral P, Pillot D, Desfossez S. 2019. Ecosystem services from Tonle Sap flood pulse: Spatial and economic analysis in Aek Phnom and Sangkae disctricts of Battambang Province, Cambodia. In: Stewart M, Coclanis P, eds. Advances in Global Change Research. Cham (Germany): Springer, pp. 123-151. https://doi. org/10.1007/978-3-319-90400-9 8.

Swinton SM, Lupi F, Robertson GP, Hamilton SK. 2007. Ecosystem services and agriculture: Cultivating agricultural ecosystems for diverse benefits. Ecological Economics 64(2): 245-252. https://doi. org/10.1016/j.ecolecon.2007.09.020.

Varis O, Keskinen M. 2006. Policy analysis for the Tonle Sap Lake, Cambodia: A Bayesian network model approach. International Journal of Water Resources Development 22(3): 417-431. https:// doi.org/10.1080/07900620500482840.

Varis O, Kummu M, Keskinen M, Sarkkula J, Koponen J, Heinonen U, et al. 2006. Integrated water resources management on the Tonle Sap Lake, Cambodia. Water Supply 6(5): 51-58. https://doi.org/ 10.2166/ws.2006.843.

Zhang W, Ricketts T, Kremen C, Swinton S. 2007. Ecosystem services and dis-services to agriculture. Ecological Economics 64 (2): 253-260. https://doi.org/10.1016/j.ecolecon.2007.02.024. 